\title{
La Ambición de Adam Smith
}

El objetivo de esta nota es presentar y discutir los principales ejes que articulan el funcionamiento de lo que, usualmente, se conoce como libre mercado. Se enfatizan tanto las condiciones bajo las cuales la asignación de recursos resultante es eficiente como los problemas que originan los denominados fracasos de mercado.

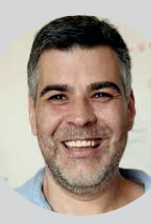

Carlos J. Ponce.

MAGÍSTER EN GESTIÓN DE PERSONAS UAH PROFESOR DE ECONOMÍA, DIRECTOR DEL DEPARTAMENTO DE ECONOMÍA, UNIVERSIDAD ALBERTO HURTADO

cponce@uahurtado.cl

\section{Introducción}

En la 'Riqueza de las Naciones' (1776), Adam Smith introdujo tal vez una de las más bellas e importantes metáforas filosóficas, la metáfora de la 'mano invisible.' Dos palabras que resumen, de manera eficaz, su creencia en la existencia de leyes naturales que conducen a un orden espontáneo y eficiente en la organización económica de las sociedades.

Desde entonces los economistas se han apropiado de la metáfora y han organizado toda su disciplina alrededor de esta idea. En este artículo, pretendo explicar, sin tecnicismos, la manera en que muchos economistas creen que funciona la mano invisible. El resto del artículo se organiza de la siguiente manera. En la sección 2 , se clarifican algunos conceptos básicos de economía. En la sección 3, se discute extensamente el teorema de la mano invisible. La sección 4 concluye.

\section{El Hombre Económico, Equilibrio y Bienestar Social}

Los economistas estudian la organización de las sociedades adoptando una posición específica respecto a la naturaleza del hombre. En economía esta posición se conoce como el hombre económico, un término que deriva del latín homo economicus.

El hombre económico actúa en su propio interés pero en un sentido amplio. Nada impide que, contrario a la creencia popular, arriesgue su vida para salvar la de otros, realice obras de caridad o done sangre de manera gratuita. Estos y otros principios 'éticos' no contradicen la naturaleza del homo economicus. Los economistas 


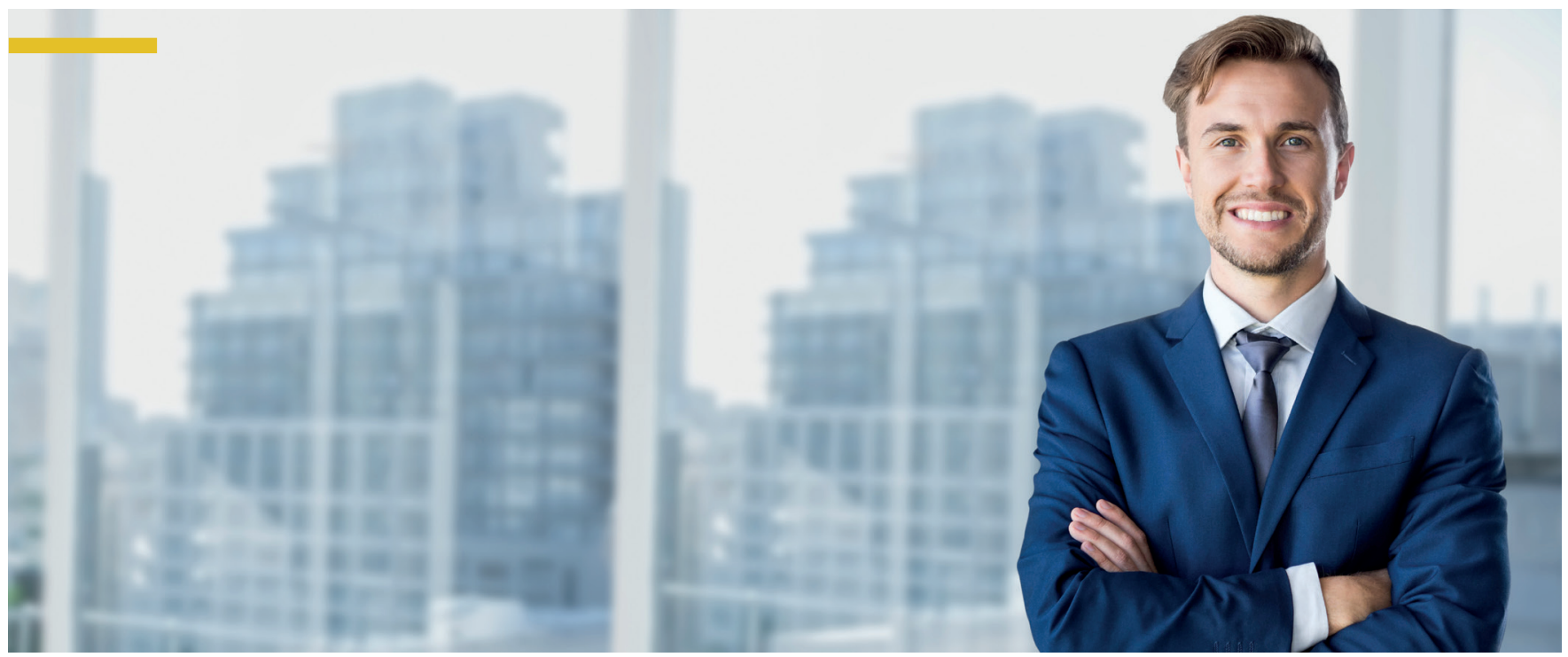

lo saben. Por supuesto, el hombre económico no está dotado de todas las virtudes que se esperarían en una persona con un sentido ético. Si las personas tuvieran un sentido ético, muchos de los problemas económicos y sociales tendrían soluciones triviales.

El hombre económico es considerado un ser racional que actúa consistentemente de acuerdo a sus preferencias y creencias o, en palabras de Hobbes (1668), de acuerdo a sus pasiones y experiencia. Por supuesto, los economistas tampoco ignoran el hecho de que la mayoría de los hombres poseen capacidad de raciocinio limitada. Prueba de ello es la extensa literatura económica que incorpora enseñanzas de la psicología a la economía.

Sin embargo, en este artículo adoptamos una mirada más tradicional y la más conocida del hombre económico. Es decir, el hombre como una 'máquina' poderosa y racional con capacidad ilimitada para resolver complejos problemas actuando siempre de acuerdo a sus propios intereses. Para agilizar la lectura, nos referimos de ahora en más al hombre económico simplemente como agente o individuo. ${ }^{1}$
¿Qué criterio podemos utilizar para predecir los resultados económicos en una sociedad determinada? ¿Cómo podemos juzgar estos resultados económicos?

Para responder a estas preguntas, conviene enfatizar que nuestro estudio estará limitado al caso más simple posible en el que un estado social se caracteriza exclusivamente por una asignación de bienes materiales entre los individuos de la sociedad. Dicho esto, para predecir los resultados económicos y sociales, los economistas utilizan el concepto de equilibrio

Como en la física, en economía, un equilibrio alude a una situación de estabilidad. En términos prácticos, un equilibrio es un estado social en el cual los individuos no tienen incentivos a modificar su conducta. En otras palabras, en un equilibrio todos los agentes escogen las mejores acciones posibles entre todas aquellas que pueden escoger. En un equilibrio, entonces, los agentes deciden su conducta, en palabras de Hobbes (1668), sopesando sus pasiones, utilizando su experiencia y considerando sus restricciones de riqueza para alcanzar el mayor bienestar posible.

No es extraño que luego de introducir este concepto, usted entienda que un equilibrio es una situación en la que se alcanza el mayor bienestar social posible. Por muy atractiva que la parezca esta aseveración, esta es incorrecta. El concepto de equilibrio es solo una herramienta de carácter técnico que nos permite a los economistas escoger, entre todos los posibles estados sociales, aquel que es más probable que ocurra. La noción de equilibrio no permite realizar valoraciones éticas o de justicia de un estado social.

\section{$C$ Si las personas tuvieran un sentido ético, muchos de los problemas económicos y sociales tendrían soluciones triviales $\$ 9$}

(1) Paradójicamente, los economistas, en una inmensa mayoría de ocasiones, consideran al hombre económico como un ser libre de envidia. 
Para valorar éticamente un estado social necesitamos introducir elementos de naturaleza normativa, elementos que son propios del dominio de la teoría de la elección social. Es imposible abordar en unos pocos párrafos los principales conceptos de esta rama de la economía. Haré hincapié solo en algunos de ellos.

Primero, estudiemos la idea exacta de un estado social mediante el siguiente ejemplo. Uma y David son los únicos habitantes de una isla desierta. Todos los días se desprenden de los árboles cien cocos y diez manzanas, los únicos dos alimentos disponibles. En este contexto, un estado social es una asignación de cocos y bananas para cada uno de los individuos. Concretamente, cinco bananas y cincuenta cocos para cada uno de ellos es un posible estado social. Por supuesto, existen muchos otros estados sociales. Por ejemplo, Uma se come las diez bananas y David los cien cocos. E incluso, aunque pueda parecerle repugnante, la asignación en la que Uma consume todas las frutas disponibles mientras que David desfallece de hambre es también un estado social posible.
¿Qué criterio podemos utilizar para juzgar un estado social? Existe un acuerdo mayoritario que el criterio más débil que un estado social debe satisfacer es el Principio de Pareto. Un estado social es Pareto eficiente si no existe ningún otro estado social alcanzable en el todos los individuos estén materialmente mejor. En otras palabras, si es posible movernos de un estado inicial, digamos el $A$, a un nuevo estado, digamos el $B$, en el que todos los individuos mejoran materialmente, entonces el estado A no es Pareto eficiente. ${ }^{2}$

En nuestra isla, supongamos que a Uma y David solo les importa su bienestar material. ¿Es entonces Pareto óptimo el estado social en el que Uma consume todos los alimentos disponibles mientras que David desfallece del hambre? La respuesta, de acuerdo a Pareto, es afirmativa. ¿Por qué? Porque en cualquier otro estado social en el que David consuma algunas frutas y mejore así su bienestar, Uma estaría materialmente peor ya que su consumo de alimentos sería menor. No podemos mejorar el bienestar de David sin empeorar el

\section{Principio de Pareto}

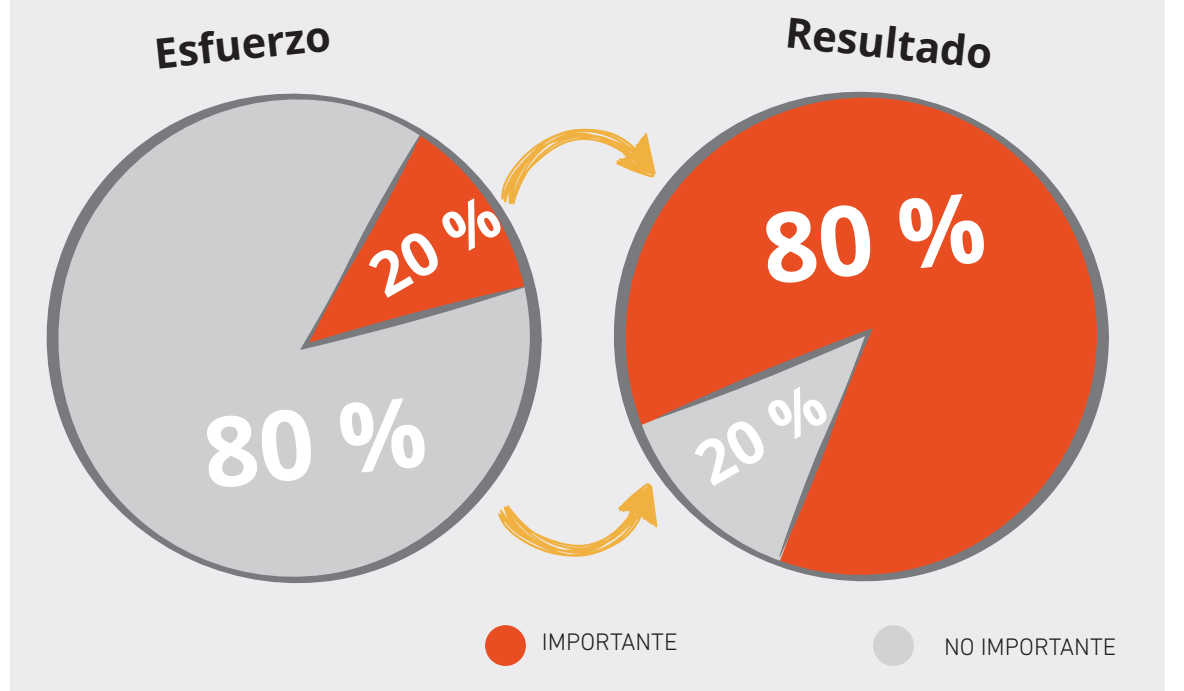

de Uma. Este estado social, por más repulsivo que le parezca, satisface el criterio de Pareto. ¿Es Pareto óptimo un estado social en la que tanto Uma como David consumen cinco manzanas y veinte cocos? La respuesta es negativa. ¿Por qué? Porque hay treinta cocos que se están desperdiciando y podrían repartirse para que ambos estén materialmente mejor. Por supuesto, si a Uma le gustaran los cocos más que a David, en un estado Pareto óptimo Uma debiera consumir relativamente más cocos que David.

Esta discusión muestra que, desafortunadamente, el criterio de Pareto no ofrece guía alguna que nos permita comparar éticamente los distintos estados sociales alcanzables.

\section{La Ambición de Adam Smith}

Multipliquemos ahora la población de nuestra isla para transformarla en un país con millones de personas como Uma y David. Aumentemos también el número de bienes materiales que los individuos pueden consumir incluyendo, por ejemplo, automóviles, cigarros, vestimenta, etc. En lugar de creer que los bienes se desprenden de los árboles, consideremos la situación, por supuesto más realista, en la que cientos o quizás miles de empresas contratan trabajadores e invierten en edificios y maquinarias para producir estos bienes.

¿Cómo determinamos en esta economía cuántos trabajadores deben estar empleados, cuántos automóviles, manzanas y vestidos deben producirse para satisfacer al menos el criterio de optimalidad de Pareto? ¿Cómo determinamos la asignación de estos bienes producidos entre los consumidores para que se satisfaga al menos el criterio de Pareto?

(2) Los economistas llaman a este concepto el criterio de optimalidad estricto. Existe una definición más débil que es más general. 
Más precisamente: ¿Qué mecanismo podemos emplear como sociedad para escoger, entre todos los estados sociales alcanzables, un estado social Pareto óptimo? Es notable que ya en 1776 el filósofo Adam Smith haya argumentado que el mecanismo de precios a través de la libre competencia fuera capaz de descubrir, de manera descentralizada, un estado social Pareto óptimo. Es esta la idea esencial de la mano invisible:

Teorema de la Mano Invisible (Adam Smith, 1776): En una economía competitiva todo equilibrio de mercado resulta en un estado social Pareto eficiente.

En otras palabras, Smith argumentaba, de manera informal y sin el rigor matemático propio de la economía moderna, que la libre competencia entre los individuos determina un sistema de precios que guía a la sociedad a implementar un estado social Pareto eficiente. Para entender el resultado considere las siguientes observaciones.

Primero, el mecanismo de precios selecciona uno entre muchos de los estados sociales alcanzables que son Pareto óptimo. Cual de estos estados la mano invisible escoge depende de la dotación inicial de recursos de cada
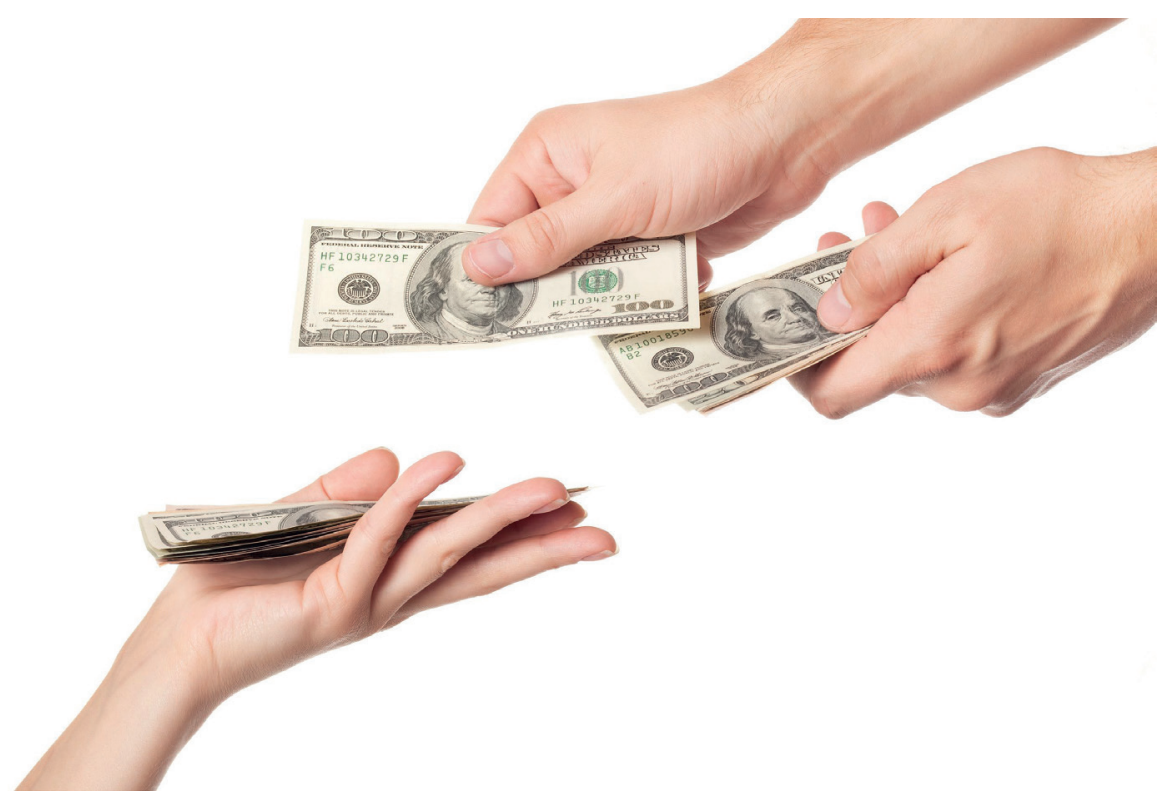

\section{L la libre competencia determina un sistema de precios que guía a la sociedad a implementar un estado social Pareto eficiente 99}

individuo. En otras palabras, depende de la distribución inicial de la riqueza entre los individuos. El teorema toma como dada esta distribución. No nos dice de donde proviene.

Segundo, la palabra clave en este teorema es competencia. El teorema se satisface solo si ningún agente económico tiene poder de mercado suficiente como para determinar de manera unilateral o cuasi-monopólica los precios de los bienes que se comercializan. Dicho de otra forma, los precios de los bienes y servicios de la economía no dependen de las decisiones de un agente específico. Por el contrario, si las empresas tuvieran poder de mercado, el estado social alcanzado podría no ser eficiente en el sentido de Pareto. Es por ello que en todas las sociedades modernas existen políticas de defensa de la libre competencia para evitar abusos derivados de poder monopólico y comportamiento estratégico de algunos actores de la economía.
Ejemplo 1. Usted debe decidir si vacuna o no a su hijo. Si lo hace, los compañeros de su niño estarán menos expuestos a las enfermedades que la vacuna previene. Cuando usted decide vacunarlo (o no), usted solo considera el hecho de que la vacuna mejora la salud de su niño (su beneficio privado) pero no considera el hecho de que vacunar a su hijo impacta positivamente en la salud de otros niños (beneficio externo). Este es el caso de una externalidad positiva: su acción mejora el bienestar de los otros niños pero usted no internaliza este beneficio externo a la hora de decidir si vacuna o no a su niño. Sin embargo, si usted no vacuna a su niño, podría afectar negativamente la salud de otros niños. Es por ello que existen los programas de vacunación obligatorios y gratuitos. De esta 


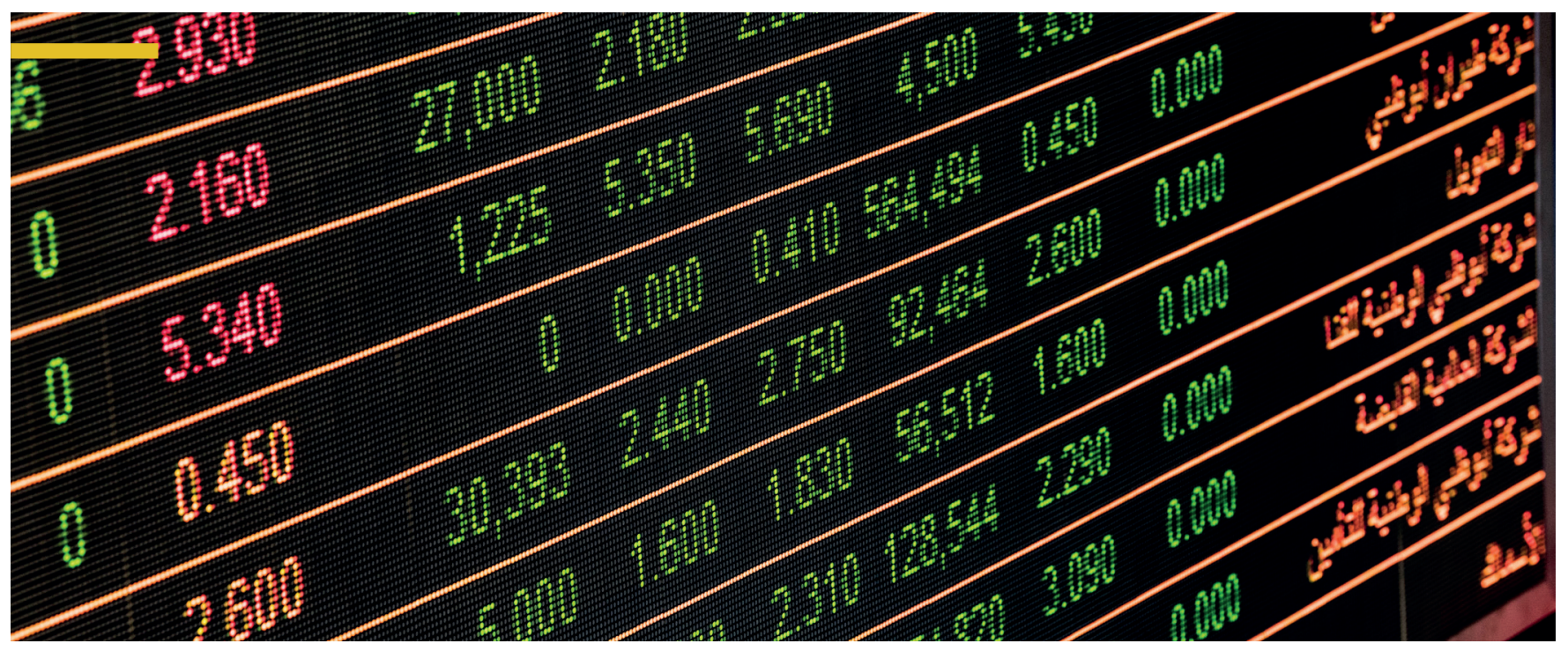

manera, los gobiernos a través de estos mecanismos obligan a los individuos a internalizar los beneficios externas que sus acciones generan

Ejemplo 2. Una empresa debe elegir si produce con una tecnología ambiental 'limpia' pero onerosa o con una tecnología ambiental 'sucia' pero barata. Supongamos, que la hora de decidir que tecnología usar, a la empresa no le importa el costo medioambiental, sino que solo le interesa el costo privado de la tecnología. La empresa no toma en cuenta que debido a la contaminación ambiental muchos niños sufrirán enfermedades respiratorias. Este es el caso de una externalidad negativa: la acción de la empresa empeora el bienestar de la comunidad pero esta no internaliza el costo ambiental cuando decide que tecnología utilizar. Es por ello que los gobiernos utilizan distintos mecanismos (multas, mercados de permisos ambientales, etc.) para que las empresas internalicen los costos ambientales que imponen.

Así, si el gobierno no interviniera, ni la empresa ni usted considerarían los beneficios o costos que le imponen al resto de la sociedad debido a su conducta. Cuando un actor solo considera sus beneficios privados e instala la tecnología que daña el medio ambiente, la mano invisible fracasa.
¿Qué podemos aprender de estos ejemplos? Aprendemos que la mano invisible funciona solo cuando el beneficio privado de sus acciones es igual al beneficio social de las mismas! Toda vez que haya discrepancias entre el beneficio privado y el social, el sistema de libre competencia no escoge estados sociales eficientes.

Permítame reformular lingüísticamente el contenido del teorema de la mano invisible. En términos alternativos, el teorema afirma que un estado social es Pareto óptimo solo cuando cada uno de los individuos de una sociedad es remunerado (premiado o castigado) de acuerdo a nuestra contribución social. ¡Solo cuando se nos premia (castiga) por el bien (mal) que hacemos la mano invisible funciona! Solo cuando la sociedad nos devuelva lo que aportamos a ella.

Permítaseme finalizar esta sección utilizando el teorema de la mano invisible para discutir, ligeramente, la polémica creada alrededor del concepto de 'lucro.' ¿Cuándo son legítimas las ganancias que recibe una empresa? ¿Cuándo son estas ganancias sobrenormales o injustificables? El teorema de la mano invisible dice que las ganancias son eficientes en el sentido de pareto cuando estas reflejan la contribución de la empresa a la sociedad. En otras palabras, los beneficios (pérdidas) de la empresa deben reflejar el cambio en el bienestar social (cambio que puede ser positivo o negativo) debido a su presencia.

\section{Conclusión}

Hasta aquí me he limitado a presentar de manera informal las ideas que subyacen al teorema de la mano invisible. Desde mi perspectiva, el teorema, más que entronizar de manera dogmática el mecanismo de libre competencia, nos muestra sus principales limitaciones y debilidades. Más aún, el teorema, desafortunadamente, no nos permite realizar valoraciones éticas o de justicia acerca del estado social que escoge la mano invisible.

Dos asuntos merecen ser tratados en artículos próximos. El primero, como enfatizamos anteriormente, es la noción de justicia social en una economía de libre competencia. El segundo, es el estudio del mecanismo gubernamental como alternativa al mercado de libre competencia. La elección de un estado social legítimo requiere no solo entender las limitaciones del mercado sino también las fallas del gobierno.

\section{Referencias}

Hobbes, Thomas (1668). Leviathan. Hackett Publishing Company, Inc.

Smith, Adam (1776). The Wealth of Nations. Oxford World's Classics.

Feldman, Allan (2005). Welfare Economics and Social Choice Theory. Springer-Verlag New York Inc. 